\title{
Digital Video as a Personalized Learning Assignment: A Qualitative Study of Student Authored Video Using the ICSDR Model
}

\author{
Laurie O. Campbell \\ University of Central Florida \\ locampbell@ucf.edu \\ Thomas D. Cox \\ University of Central Florida
}

\begin{abstract}
Students within this study followed the ICSDR (Identify, Conceptualize/Connect, Storyboard, Develop, Review/Reflect /Revise) development model to create digital video, as a personalized and active learning assignment. The participants, graduate students in education, indicated that following the ICSDR framework for student-authored video guided their video creation process, resulting in focus for their ideas, and increasing motivation to learn more about their content. Finally, the participants indicated that creating a digital video was an authentic and personalized learning experience that fostered personal choice and voice and peer collaboration. Evidence from the qualitative study supports students following a development framework for video creation.
\end{abstract}

Key Words: Personalized Learning, student-authored video, ICSDR, active learning

The predominance of social media and the increased accessibility of mobile devices with cameras are known contributors to the consumption and development of digital video. The ubiquitous access and ease of use of video recorders on smartphones, tablets, and cameras and the convenience of video sharing sites have more adults than ever recording, capturing, and uploading video to Internet sharing sites. YouTube, the largest video social sharing website, boasts "over a billion users who watch millions of hours of video daily (YouTube, 2016). Digital video flourishes. Over $72 \%$ of adults, who use the Internet, also use online Internet video-sharing (Anderson, 2015). Over 400 hours of new videos are uploaded to YouTube in a one-minute period (Wojcicki, 2015).

Video sharing sites and their related tools enable viewers to move from being consumers of video to being producers of video. The simplicity of capturing and uploading video has facilitated the billions of hours of digital videos typically created for informational and entertainment purposes by individuals, business, government, and education. The exponential growth of video in the past 10 years has influenced pedagogical approaches in the classroom. For instance, in a recent study by Kaltura (2015), 24\% of participants surveyed identified that over $50 \%$ of classes at their institution regularly used video in instruction while $83 \%$ of the educators 
believed that students will be creating more video content in the future $(N=948)$. However, educators agree that more experience and training is needed for authoring video. Providing a framework for digital video creation may scaffold the work flow of video creation.

It is known that having students create digital video can be an active and authentic learning assignment (Dumova, 2008; Kearney \& Schuck, 2004); yet, it is unknown if digital video creation is a personalized learning activity. It is the authors' contention that learners creating and authoring a video are not only engaged in active, authentic learning but are also engaged in personalized learning. As a student generative activity, students' voice and choice are observed in well-crafted, edited digital video. Imploring the question, does the addition of a digital video development model support or hinder the creation of digital video as a personalized learning activity?

With the need for providing training in authoring video and the desire to engage higher education students in active, authentic and personalized learning experience, the aims of the study were to (a) identify the state of student created video among the current population; (b) describe the ICSDR model; (c) analyze students' perceptions of incorporating the ICSDR framework to make a student created video; and (d) identify the assess personalized learning aspects of video assignments. For the purpose of this paper, digital video refers to video captured with a personal device or camera that can be found on video hosting websites, like YouTube, Vimeo, TeacherTube, SchoolTube, or a local on file storage. "Digital video" referenced in this paper does not include professionally created video, video shorts, or full featured film.

Within this study, student created or student authored video denotes: video recorded in a natural or authentic setting, audio tracks (e.g. voiceovers, audio recorded in an authentic setting, and or curated original music). Student created or authored video signifies that the student edited the raw video and audio that they generated resulting in finished and complete video as an outcome. Student created or student authored video (used synonymously) does not refer to a multimedia slide presentations, animated video, or still images that have been animated and set to music.

\section{Literature Review}

\section{Students as Consumers of Video in the Classroom}

Video is often used in higher education for instructional and tutorial purposes (Campbell, 2012, Martin \& Martin, 2015; Shipper, 2013, Yarning \& Yit-Liang, 2015; Wen-Jung \& Cigas, 2013). Teachers assign students to watch videos both in and out of the classroom for the purpose of introducing a topic, watching recorded lectures, encouraging discussions, learning a second language, explaining activities or assignments, and recording screencasts (step by step instructions to complete a procedure or process on a computer). In some cases, these uses bring a multimedia dimension to static instruction (Ljubojevic, Vaskovic, Stankovic \& Vaskovic, 2014; Viteri, Clarebout, \& Crauwels, 2013). Students indicate that video helps them acquire knowledge because they are able to stop, start, and replay a video until they feel they understand the material being presented.

Using video in the classroom has been recognized to motivate students at all age levels (Ballast, Stephens, \& Radcliffe, 2008; Gunter, 2012; Ljubojevic, Vaskovic, Stankovic \& Vaskovic, 2014; Spires, Hervey, Morris, \& Stelpflug, 2012;). Students’ motivation to watch video extends beyond watching teacher assigned videos for a grade to watching videos of their own choosing either to develop a deeper understanding of content, to complete a process or procedure, 
or for their own enjoyment. However, the length of a video and the content makes a difference as to how much of the video is watched. Martin and Martin (2015) observed that students do not watch academic tutorial videos over 3 minutes in length. Others' research noted that students tend to watch some or parts of video skipping around to the parts they felt pertained to them the most (Bowles-Terry, Hensley, \& Hinchliffe, 2010).

\section{Students as Producers of Video in the Classroom}

A digital video assignment moves students from being consumers to be producers of their own content. Incorporating digital video as a generative assignment in higher education affords the demonstration of acquired understanding of a body of knowledge (King \& Cox, 2011). A range of other known student created digital video assignments consist of personal introductions, encompassing an aspect of their lives, telling a personal narrative (Hughes, \& Robertson, 2010; Ballast, Stephens, \& Radcliffe, 2008), recreating a historical event, (Debiase, 2008; Hofer \& Swan, 2006) creating a book trailer (Gunter, 2012; Kenny \& Gunter 2010; Gunter \& Kenny, 2008). Typically, the guidelines and assessments of digital video assignments include a teacher-created checklist of required elements (both content and technical) and or a rubric to support assessment. Literature describing the genres of student created digital video assignments does not indicate that students were provided a framework or model to scaffold the digital video workflow and development processes. There is a paucity of literature describing models for video creation.

Student created video is only limited by the student's idea, creativity, and technical abilities. The cohesiveness and quality of a video of a student created video requires more than just capturing video and putting a title on it. Like writing an essay, often students do not know where to begin to create a video beyond the technical aspects of video creation. Further, students do not edit video often because they lack the skills or the self-efficacy to do so as the students in this study indicated in their pre-survey responses and discussions. Others feel it takes too much time to edit a video. Some student authored digital video may appear not to have a cohesive purpose, can be too long, or the converse may be the case videos may have great technical qualities with minimal substance. All of these reasons can contribute to the quality of student authored video. Just as students benefit from instruction and strategies on how to write a succinct paper, it is our hypothesis that a framework for creating and curating student authored video would be useful in academic video development.

\section{ICSDR: A Framework for Student Authored Video}

Knowing the need for guidance for student-authored video development (Hofer \& Swan, 2006), a model was developed to aid teachers in implementing video assignments. ICSDR (pronounced ick-stir), an acronym for Identify, Conceptualize and Connect, Storyboard, Develop, Review, Reflect, Revise, is a model that provides a pathway and framework for students to follow when producing a video (See Figure 1). The model begins at development of concept, requires peer feedback, and includes opportunities for revision, and reflection before the student finalizes the video. Similar to the draft and revision process of writing an essay, student authored video benefits from drafting, editing, and reviewing its development prior to being completed. The ICSDR model has been implemented with elementary, middle school, undergraduate, and graduate students (Campbell, 2012). 


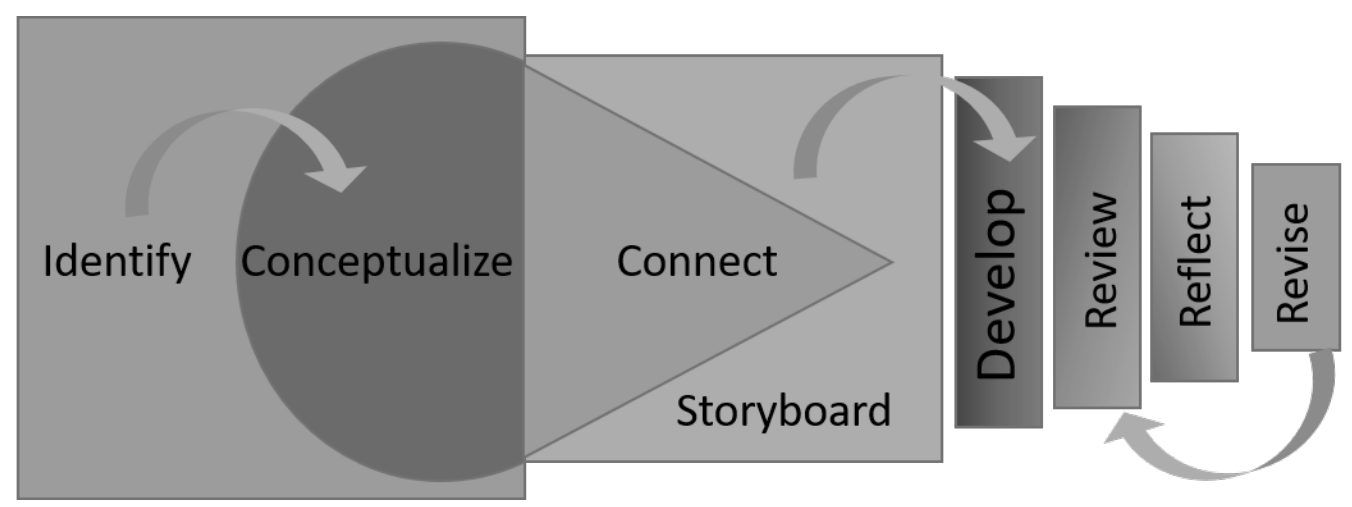

Figure 1. ICSDR Model for student-authored video

Using a grounded theory approach to development, the ICSDR model was developed with varying populations of students as a means to quantify a process for student authored video development. The model was meant to fill an observed need noted by faculty members from both K-12 and higher education. The ICSDR framework has been applied to student created original digital video as well as student curated digital video (Campbell, Planinz, \& Miller, 2016). Each step in the model was refined over a period of time through student comment, faculty use, observations, and video development artifacts (brainstorming, storyboarding, peer review analysis, and the videos themselves).

\section{Personalized Learning}

Personalized learning considers students first. The National Education Technology Plan's (NETP) (Department of Education, 2010), definition of personalized learning incorporates the familiar terms of differentiation (Tomlinson, 2000), individualization, and personalization and emphasizes the facilitation of personalized learning occurring through the use of technology. Specifically, personalized learning includes teaching and learning governed by student's learning needs, preferences, interest, and pace.

The culture of a personalized learning environment values the learner's individual needs and abilities when meeting standards, benchmarks, and competencies. Assessments and feedback guide the learning path for students on an individualized basis, meaning activities and assignments may vary. Further, there is mindfulness towards independent learner agency, nurturing independent learning and thought, while still collaborating with peers. Personalized learning, as a pedagogical method or approach, practices individuality and varied methods, pacing, objectives, and content for student success. The learner is empowered and makes learning choices within assignments allowing for customized learning experience (Grant \& Bayse, 2014) incorporating a wide variety of activities and assignments.

Assignments in a personalized learning environment, capitalize on the key principles of personalized learning. An assignment such as a student created video can share the hallmarks of personalized learning. Students choose the content, pursue relevant content, produce their representation of knowledge, participate in reflective personal and collaborative feedback and assessment and finally publish their work. It is within this context that the graduate students in this study created one-minute videos as a personalized learning activity. 


\section{Methodology}

\section{Research Design}

A qualitative research design for the study was used from a phenomenological approach. Descriptive statistics were analyzed from the pre and post surveys of self-reported data. Other data collected included, online group discussions, notes from peer conversations, brainstorming records, storyboards, the videos themselves, and the students' reflections.

Research Question 1: How does following the ICSDR model, for student authored video, influence or effect the outcome of the video?

Research Question 2: What are graduate students' perceptions regarding the ICSDR model for student authored video?

Research Question 3: Did the students consider the student created video a personalized learning experience and what did the students value in the assignment?

For question 1: Videos were analyzed for change from brainstorming to the final posted videos. The videos were coded to see if they aligned with the author's initial objective. Further, students wrote a reflection about the processes to complete the video. These were analyzed for indicators of influence. For questions 2 and 3: Using an open-ended questionnaire, an analysis of focus and peer group conversations, and online discussions, students perceptions were coded and emerging themes were documented.

\section{Participants and Setting}

The participants $N=10$ for the study were all female graduate students enrolled in an education program at a large Southeastern University attending the same class. Eighty percent of the students were state certified teachers working on a Master degree program in content area disciplines such as Science, Math, and Reading. The other $20 \%$ of the students were not currently in the K-12 classroom but in other educational training roles. Consent to participate in the study was obtained from all participants.

The technological skills of the students varied from novice to average proficiency as selfidentified. Seventy percent of the students indicated that they had made at least one video prior to the class for personal reasons often using their smartphone or tablet. However, only $20 \%$ of the students indicated that they previously made a video as part of a class assignment (individually or collaboratively) and $40 \%$ of the students had assigned their own students to create a video for an assignment. Their students used PowerPoint or PowToon's video as part of an assignment. These graduate teachers K-12 students curated images and added sound. They did not capture live authentic video themselves nor were they required to provide a plan prior to the final product.

The format of the class was a hybrid instructional model. Classes were conducted either face to face on the campus of the University or through synchronously using Google Hangouts every other week or every three weeks. The class materials and management was conducted through Canvas, a Learning Management System (LMS). Some of the discussion for this study 
was mediated through the LMS, while the rest was conducted live through Google Hangouts, or in the Face to face classroom.

\section{Procedure}

Prior to the introduction on a student created video unit of instruction, students knew they would be making a one-minute video that they would capture with a mobile device. Basic parameters, for the assignment were discussed. Elements and requirements for the video included telling a story, a time restriction of no longer than a minute, live action video that the students had personally captured, and the video was to be based on a measurable content objective. The objective would indicate a behavior or action that a student would perform as a result of watching the video. For instance, a student who taught marketing and business, objective was for students to be able to define the term return on investment. The students were not to make a screencast, a lesson, a presentation, or a tutorial. The purpose of the video could be an introduction to content that would be taught in a lesson, an explanation of an abstract word or concept, or a means to spark interest of content. Since the graduate students were all practicing teachers or trainers they chose to create a video that would help them in their current teaching assignment. Students were then asked to determine a measurable objective for their video.

Then students completed a Qualtrics survey indicating their experience with student authored video (either as a teacher or student), and recorded a potential idea and objective of their video. After the pre-survey, students were assigned to watch a presentation about the ICSDR framework. At the next class period and after watching the presentation students engaged in a face to face discussion related to how they had used student created video in their own teaching practice. During this discussion, students reviewed and discussed the model with each other and the instructor. Peer groups were established for feedback and review, and a collaborative student driven timeline was developed to provide structure to the assignment. At this point, students confirmed their topic and objective of their video.

Then students received a digital copy of the brainstorming collaboration document to complete over the next week. After conversing with peer groups and others (e.g. colleagues, friends, and even family members), the students finalized their topic and wrote a measurable objective for their video. Students were then given digital storyboards (See Figure 2) and the assignment deadlines were established based on collaboration between students and the instructor. Over the next week, students completed the storyboards for their video and consulted their peer groups through online discussions and phone conversations resulting in revisions to storyboards and scripts. Then, the students completed the technical aspect of the assignment which included shooting and editing the raw video, curating and editing sounds, and recording voiceovers. After completing the first draft of the video, students posted a link to the video for peer review within the peer group and within the class. Using a feedback checklist as a guideline of required elements, students self-reviewed and peer reviewed the student created video. Students reviewed the comments about their video from themselves and others and made modifications before posting a final version of the video. At the conclusion of the assignment after final edits were completed and videos were posted, students watched each other's final videos. They turned in a private openended reflection of the assignment (process and product) and completed a post assignment survey in Qualtrics. 


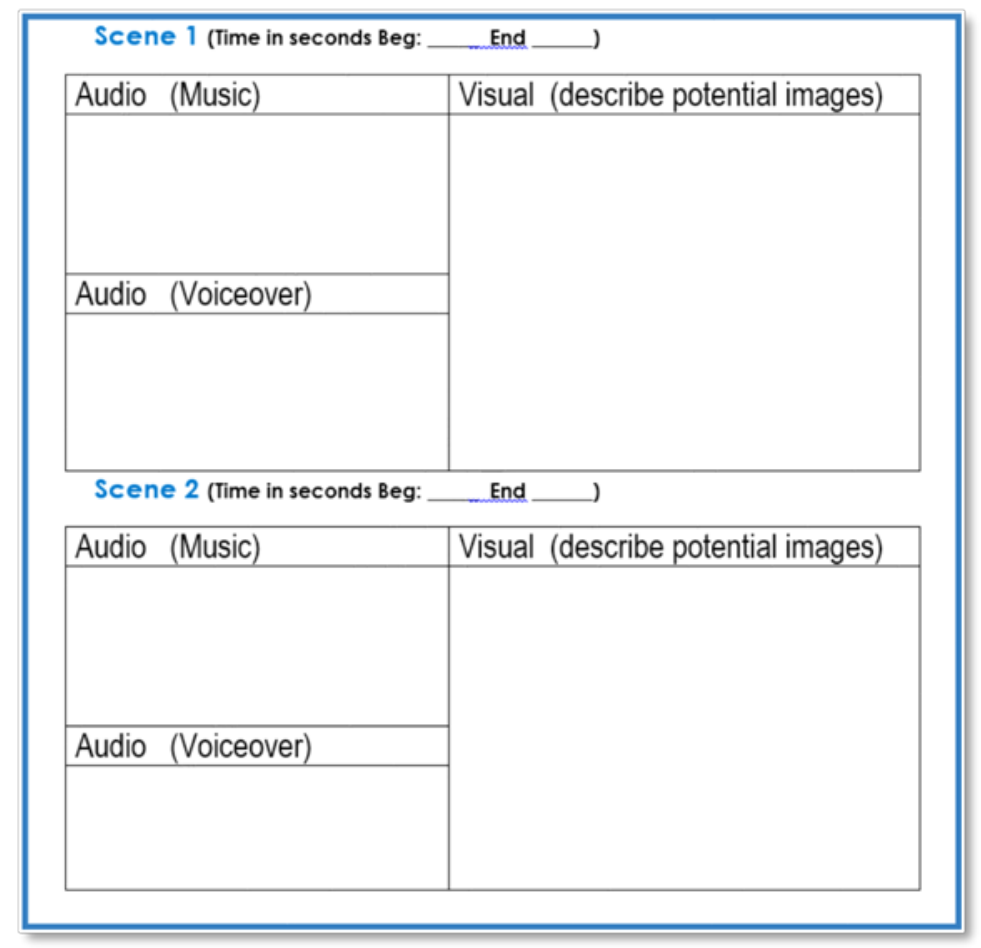

Figure 2. Digital Storyboard template.

\section{Results}

\section{Research Question 1}

How does following the ICSDR model, for student authored video, influence or effect the outcome of the video? After looking at the assignment artifacts (e.g. brainstorming record, storyboards, and feedback discussions, the students concluded that all completed student videos evidenced change from the previous step at many of the phases of the ICSDR model. Three themes emerged from this question include: objective importance, peer feedback related to editing and instruments.

Objective Importance. In $80 \%$ of the videos, the initial objective was clearly met as determined by the participants themselves and their peers. One student comments summed up the relevance of referring to the objective throughout video development. She indicated, "The objective kept me focused so I did not chase 'shiny distractions' or give my learners too much information at once.” Of the $20 \%$ that did not meet the objectives, one student indicated that after the second round of peer evaluations, she felt that she needed a new concept and did not go through the initial stages for the second video she created. However, she did follow the later steps from storyboarding phase forward. In the other case, the student indicated she was aware that she did not stick to her initial objective. Even though her peers mentioned this to her and made suggestions in the storyboard review stage, she chose not to revise her storyboard or to consider their suggestions. In her final reflection, she noted that she wished she had either followed or revised her initial objective because she felt her video did not communicate her ideas and lacked the depth of her peers' videos.

Peer Feedback Related to Editing. Throughout the online discussions at each step in the framework that required peer feedback students often provided pragmatic advice to their peers. 
One such comment exemplifies how the collaboration ultimately guided change within the video at the storyboard phase. The student said in a discussion, "I thought about the peer comments and then decided there would be value in reworking my video. The audio did not change too much, however the visual completely changed. If I did not make the edits based on my peers' suggestions at the storyboard stage, I am not sure I would have done the changes. I would not have the video I have today and I probably would not be as happy with the assignment. I can't wait to show my own students from the brainstorming sheet to the completed video.”. Others students explained that peer feedback made them consider their ideas and work in a way that they would not have had they only self-reflected about that phase of their video.

Instruments: Brainstorming and Storyboards. Generally, students indicated that the storyboards were useful as a roadmap and even though they may have veered from them at times it still helped to provide cohesiveness during video production. The majority of the students indicated that they referenced their brainstorming sheets even while they were capturing video, others stated that they did not feel the brainstorming process was necessary since the brainstorming paper did not reflect their final video product but all indicated that the storyboards were important. Finally, one student stated, "The easiest part of the assignment was creating the storyboard. After creating the brainstorm document, I was able to go through the storyboard quite easily to produce a story line of my video."

Research Question 2

What are graduate students' perceptions regarding the ICSDR model for student authored video? Students' perceptions were collected through the post survey, personal reflections, and class discussions. Students were in favor of using a model for video development and would consider using the model with the K-12 learners that they teach (see Table 1). From their personal reflections students specifically indicated the model was beneficial. One student wrote, "The ICSDR model helped to make sure the story aspect of the video was apparent." Another student noted, "The ICSDR model helped me significantly because it created an outline for what was needed and required of the video as I followed through the steps, the storyboard and creation of the video came together much easier than expected. I feel like I made a video that others in my school could use.”

\section{Table 1.}

Post Survey Perspectives after completing the student created video assignment

\begin{tabular}{|c|c|c|c|}
\hline Questions & Yes & No & Maybe \\
\hline $\begin{array}{l}\text { Would you assign a one-minute video assignment for your K-12 or } \\
\text { other students when you teach? }\end{array}$ & 6 & & 4 \\
\hline $\begin{array}{l}\text { Would you use the ICSDR model for student created video for } \\
\text { yourself? }\end{array}$ & 10 & & \\
\hline $\begin{array}{l}\text { Would you use the ICSDR model for student created video with your } \\
\text { K-12 or other students? }\end{array}$ & 10 & & \\
\hline $\begin{array}{l}\text { Does your school have the technology for students to do a one- } \\
\text { minute video project? }\end{array}$ & 9 & & 1 \\
\hline $\begin{array}{l}\text { I learned something about making a one-minute video using the } \\
\text { ICSDR model? }\end{array}$ & 10 & & \\
\hline
\end{tabular}

Note: Students had the option of including additional comments for each question 
Completion and Timing. Students initially indicated that they thought it might take 8 hours or less to complete the assignment from initial concept to final video and for the most part this estimation was accurate. Students reported that they completed the storyboard portion in 1 to 2 hours and they spent the rest of the time shooting the video, finding music or completing voiceovers, and editing the raw video and audio. Most students did not capture raw footage and edit the video on the same day. Instead, they organized their work over several days. Where initial edits may have taken hours, the final edits after the last round of peer reviews took from 15 minutes to an hour. Videos were required to be one minute or less. Some students felt that the one-minute restriction caused them more editing time then they initially anticipated. For 2 of the students they rationalized that if the video could have been any length (5-7 minutes) they would have less editing to do. All students indicated that they had a learning curve in regard to video editing so in the future it may take them less time to create a video.

Students' response varied as to whether they would assign creating a video to their own students, of the $20 \%$ of the $40 \%$ students that they might require a video assignment, indicated that the age and grade of their students would probably prohibit them from requiring a video assignment. However, if they had older peers to help they would consider it a viable assignment. While all would use the ICSDR model for their own creation of videos, most thought authoring a video took more time to do than they had in a day to devote to developing curriculum in their classroom.

\section{Research Question 3}

Did students consider the student created video a personalized learning experience and what did the students value in the assignment? All of the students indicated that student created video was a personalized learning experience as defined by The National Education Technology Plan's (NETP) (2010). The students indicated that student created video following the ICSDR model included key elements found in personalized learning such as autonomy in decisions, collaboration, student voice and choice, while incorporating various technologies for creation and feedback. Student choice, content and technical skills gained, and collaboration were the themes evidenced in the reflections and discussions related to personalized learning.

Student Choice. Pertaining to student choice, the students chose the content of the oneminute video, their audience. The content of their videos was designed for their own K-12 students or trainees. For instance, one teacher introduced Monet to her $4^{\text {th }}$ grade students through a oneminute story while another student created video that introduced the math concept of greater than. She captured video at a local alligator farm so students could see the open mouths of the alligators. From the assignments inception, students chose the objective and the path to reach the objective. If students felt they needed more content or skills they chose the means to gain the knowledge they required. Students were not obligated to follow advice from their peers instead they could engage in a discussion and make their own choices. Collectively, the students chose deadlines for each stage of the model and how they were going to complete the assignment.

Academic Content and Technical Skills Gained. One surprising result of the study was that $40 \%$ of the students indicated that they learned more about the content as they were planning and developing the content for the video. Some attributed their new knowledge to researching more information to create a story that they told in the video. One person indicated that a peer reviewer asked her a question about her content that she did not know so in search of an answer she learned more about her topic. Twenty percent of those that did not learn new content stated that their lessons were at a basic level and they did not feel there was any room for them to learn new content. 
Participants (80\%), expressed that they learned a new technical skill as a result of editing the video and audio they recorded. Some indicated they watched a short screen captured type video to aid them in how to use the program. Two of the students noted that the videos they watched to learn a technical skill were over 6 and 9 minutes long respectively. Each learner expressed that they skipped through to the part they felt pertained to them. They concluded that shorter videos were better for their own learning. The videos they watched to learn the technical skills were not assigned; rather, they found the video on their own and even shared them with their classmates through an online shared space.

Collaboration. The students repeatedly valued the collaborative aspect of this model because they felt collaboration allowed them to create a better video than if they had been working alone. One student mentioned that initially she felt like her storyboards were detailed and were easy to follow. However, after the peer review she realized her storyboards would benefit from revision as they needed more detail to tell a complete story. Another student noted that she asked her junior high students to collaborate as she was developing her ideas since they were going to be the primary audience of the video. She felt that their collaboration made her video more relevant to their interests.

\section{Discussion}

\section{Findings}

The findings of the study include that these learners indicated that following the ICSDR model influenced the creation and production of their student authored video. Participants' responses revealed that ICSDR model was a useful framework for student created video. Students noted that the model fostered revision and collaboration that might not have happened if they did not follow the model. Students indicated that the instruments (e.g. brainstorming template and storyboards) within the model guided the digital video development process while still affording the creativity and developmental autonomy.

Students' perceptions regarding the ICSDR model related to beneficial collaboration, the actual timing to complete the assignment, and the pros and cons of following a model. Finally, the findings regarding student created video being a personalized learning assignment implied that student created video is a personalized learning activity. Students' noted because the activity was authentic, fostered student choice, provided outlets for collaboration and feedback that they were driven more to learn more to complete the video.

Limitations, and Implications of the Study. A potential limitation of the study was the sample size; meaning generalizability is limited. In light of this constraint, the study could be conducted again with a greater number of participants. Because the modality of the study happened in a hybrid setting the replicability of the study while possible may yield different results if conducted in a different type of classroom (e.g. hybrid, fully online, or fully face to face) (Blackmon, 2012). According to the students in this study, the creation of the video was aided by the ICSDR model but it is unknown if the viewers of the video would concur. A future study could include audience perceptions.

While this study did not specifically address the length of video students created, in the final reflections half of the students in this study felt that the required time limits (meaning the video they created were limited to one minute or less) hampered their ability to create the video they wanted to create. Their preferred video length would have been 5 to 7 minutes even though 
they noted that they themselves would probably not watch an assigned video that was that long. In follow up discussions, $80 \%$ of the students indicated that when assigned to watch a video over 57 minutes they tended to only watch parts of videos up to about 3 minutes in length which is similar to Martin and Martin (2015) findings. However, our participants stated that they do watch videos that are longer in length if they have a personal motivation to watch. Based on these unintended results, further investigation of ICSDR model relative to varying time constraints is warranted.

\section{Conclusion}

Based upon their own experiences as learners and their current role as teachers, the participants in the study, indicated that there is a need for framework or design model to scaffold student created video at every grade level through graduate school. In the students' opinion, based on their video creation experiences in this study, the ICSDR model facilitated the video creation processes to produce a concise video in comparison to other video development experiences of their own or when their students created videos. The participants attributed the quality of their video to their own quality control after review from their peers at several points through development of the video.

Germane to personalized learning and video creation, the student created or authored digital video assignment following the ICSDR model was perceived by the participants as a personalized learning activity. How the participants' created the video, the content of the video, the tools used for digital video creation reflected students' choices which motivated the students to produce a video that they would use again and again. Following the ICSDR video development model scaffolded the design process. The use of the ICSDR model in a personalized learning assignment was not considered a barrier or hindrance but was deemed a support to the digital video development process according to the participants. The reviews and discussions with peers after the storyboards were created, the pre and post editing of the plan prior to filming, and the peer review checkpoints throughout the creation of the digital videos were denoted as the most helpful aspects of the ICSDR model. The majority of the graduate teacher participants remarked that they would incorporate the ICSDR model in their own classrooms.

The study provides implications to the literature: (a) the importance of personalized learning assignments and (b) the usefulness of student authored or created digital video. Specifically, within the student authored or created digital video, research studies are limited especially related to their design and development. Student created video as a personalized learning activity merits more research with other populations and other context. 


\section{References}

Anderson, M. (2015). 5 facts about online video, for YouTube’s 10th birthday. http://www.pewresearch.org/fact-tank/2015/02/12/5-facts-about-online-video-for-youtubes-10thbirthday/

Ballast, K., Stephens, L., \& Radcliffe, R. (2008). The effects of digital storytelling on sixth grade students' writing and their attitudes about writing. Proceedings of Society for Information Technology and Teacher Education International Conference 2008, Chesapeake, VA: AACE, 875-879.

Blackmon, Stephanie J. (2012). "Outcomes of chat and discussion board use in online learning: A research synthesis." Journal of Educators Online 9, (2).

Bray, B., \& McClaskey, K. (2013). A step-by-step guide to personalize learning. Learning \& Leading with Technology, (7). 12.

Bowles-Terry, M., Hensley, M. K., \& Hinchliffe, L. J. (2010). Best practices for online video tutorials in academic libraries. Communications in Information Literacy, 4(1), 17-28.

Campbell, L. O. (2012). Pre-service teacher's perceptions about the "One Minute Vocabulary Video Project”. In P. Resta (Ed.), Proceedings of Society for Information Technology \& Teacher Education International Conference 2012 (pp. 1341-1346). Chesapeake, VA: Association for the Advancement of Computing in Education (AACE).

Campbell, L.O., Planinz, T. \& Miller, M. (2016). Integrated digital storytelling: An active learning strategy for building 21st century skills. In Proceedings of EdMedia: World Conference on Educational Media and Technology 2016 (pp. 1820-1825). Waynesville, NC: Association for the Advancement of Computing in Education (AACE).

Clark, R. \& Feldon, D. (2014). Ten common but mistaken principles of multimedia learning. The Cambridge Handbook of Multimedia Learning. $2^{\text {nd }}$ Ed. New York: Cambridge University Press.

Debiase, M. (2008). Video documentaries as content and tools to new learning experiences: recreating history with shared resources. In J. Luca \& E. Weippl (Eds.), Proceedings of EdMedia: World Conference on Educational Media and Technology 2008 (pp. 2839-2845). Association for the Advancement of Computing in Education (AACE).

Department of Education (ED), Office of Educational Technology. (2010). "Transforming American education: Learning powered by technology. National Education Technology Plan, 2010." US Department of Education.

Engin, M. (2014). Extending the flipped classroom model: Developing second language writing skills through student-created digital videos. Journal of the Scholarship of Teaching and Learning, 14(5), 12-26. 
Grant, P. \& Bayse, D. (2014). Personalized learning: A guide for engaging students with technology. Eugene, OR: International Society for Technology in Education.

Gunter, G., \& Kenny, R. (2008). Digital Booktalk: Digital media for reluctant readers. Contemporary Issues in Technology \& Teacher Education, 8(1), 84-99.

Gunter, G. A. (2012). Digital Booktalk: Creating a community of avid readers, One video at a time. Computers in the Schools, 29(1/2), 135-156.

Hofer, M. \& Swan, K. (2006). Knowledge in action: A case study of a middle school digital documentary project. Journal of Research on Technology in Education, 41(2). 179-200.

Hughes, J., \& Robertson, L. (2010). Transforming practice: Using digital video to engage students. Contemporary Issues in Technology and Teacher Education, 10(1). http://www.citejournal.org/vol10/iss1/languagearts/article2.cfm

Kenny, R., Gunter, G. (2004). Digital Booktalk: Pairing books with potential readers. Association for Educational Communications and Technology.

King, K. \& Cox, T. (2010). The professor's guide to taming technology: Leveraging digital media, web 2.0 and more for learning. IAP - Information Age Publishing, Inc., 2010.

Ljubojevic, M., Vaskovic, V., Stankovic, S., \& Vaskovic, J. (2014). Using supplementary video in multimedia instruction as a teaching tool to increase efficiency of learning and quality of experience. International Review of Research in Open and Distance Learning, 15(3), 275-291.

Martin, N. A., \& Martin, R. (2015). Would you watch it? Creating effective and engaging video tutorials. Journal of Library \& Information Services in Distance Learning, 9(1/2), 40-56. doi:10.1080/1533290X.2014.946345

Mayer, R. E. (2009). Multimedia learning. $2^{\text {nd }}$ Ed. New York: Cambridge University Press.

Shipper, F. (2013). If a picture is worth 1,000 words, is a video worth 3,000 words?:A review of video resources Available for use in today's management classroom. Academy of Management Learning \& Education, 12(4), 684-686.

Spires, H. A., Hervey, L. G., Morris, G., \& Stelpflug, C. (2012). Energizing project-based inquiry: Middle-grade students read, write, and create videos. Journal of Adolescent \& Adult Literacy, 55(6), 483-493.

Tomlinson, C. A. (2000). Differentiation of instruction in the elementary grades. Carol Ann Tomlinson. Champaign, IL: ERIC Clearinghouse on Elementary and Early Childhood Education, University of Illinois.

Viteri, F. Clarebout, G. \& Crauwels, M. (2014). Children’s recall and motivation for an environmental education video with supporting pedagogical materials, Environmental Education 
Research, 20:2, 228-247, DOI: 10.1080/13504622.2013.771734

Wen-Jung H., \& Cigas. J. (2013). Short videos improve student learning in online education. Journal of Computing Science in Colleges. 28, 253-259.

Wojcicki , S. (2015). Industry keynote with YouTube CEO.

https://www.youtube.com/watch?v=06JPxCBlBh8

Yarning, T., \& Yit-Liang, T. (2015). Effects of commercial web videos on students' attitude toward learning technology. International Journal of Information \& Communication Technology Education, 11(3), 20-29. doi:10.4018/IJICTE.2015070102 